\title{
Epiderme dos segmentos foliares de Mauritia flexuosa L. f. (Ârecaceae) em três fases de desenvolvimento
}

\author{
Mahedy Araújo Bastos PASSOS ${ }^{1}$, Maria Sílvia de MENDONÇA²
}

\section{RESUMO}

São apresentados os dados anatômicos da epiderme dos segmentos foliares de Mauritia flexuosa L. f. (Arecaceae) em três fases do desenvolvimento. Os segmentos foliares foram analisados em toda a extensão do limbo. As células intercostais da epiderme das faces adaxial e abaxial evidenciam-se com paredes sinuosas, retangulares e orientadas longitudinalmente em relação ao eixo do segmento foliar com acentuada presença de corpos de sílica esférico-espinulosos. As células epidérmicas da região costal de ambas as faces apresentam paredes retas e variam entre curtas, longas e arredondadas. Os tricomas são simples, unicelulares, longos, com base mais alargada. Os segmentos foliares de $M$. flexuosa são anfiestomáticos com estômatos tetracíticos. Em secção transversal a epiderme foliar é uniestratificada com câmara subestomática ampla. Os resultados obtidos não demonstraram variaçôes expressivas entre as três fases de desenvolvimento e os caracteres encontrados parecem ser comuns a outras palmeiras.

\section{PALAVRAS-CHAVE}

Anatomia, folha, buriti

\section{Epidermis of leaf segments from Mauritia flexuosa L. $f$. (Arecaceae) on three phases of development}

\section{ABSTRACT}

Anatomic data on the epidermis leaf segments from Mauritia flexuosa L. $f$. (Arecaceae) are presented on three phases of development. Leaf segments were analyzed on the all extension of leaf. Both adaxial and abaxial epidermal cells stand out with sinuous walls, rectangular and longitudinally oriented to the foliar axis with the marked presence of spherical-spiny silica bodies. The back epidermal cells of both surfaces present straight walls and vary among short, long and round. Trichomes are unicellular, simple, long, with a wider base. Leaf segments from M. flexuosa are anphistomatic with tetracitic type stomats. In a cross-section the leaf skin is unistratified with a broad substimatic chamber. The findings obtained showed no significant variations among the three phases of development and the characters that were found appear to be common on other palm trees.

\section{KEYWORDS}

Anatomy, leaf, buriti

\footnotetext{
${ }^{1}$ Curso de Pós-graduação em Botânica, PPG-BTRN do INPA/UFAM. e-mail: mahedy@bol.com.br

${ }^{2}$ UFAM/FCA/LABAF Av. Gen. Rodrigo Otávio J. Ramos, n 3000, Coroado, 69077.000 Manaus- AM, Brasil. e-mail: msilvia@ufam.edu.br
} 


\section{INTRODUÇÃO}

As palmeiras constituem-se em um dos grupos de plantas mais importantes para a regiāo Amazônica por estarem diretamente relacionadas à subsistência do homem desta região. Entre as palmeiras mais utilizadas destaca-se Mauritia flexuosa L. f., conhecida popularmente como buriti, é encontrada no seu estado silvestre em várias formaçōes vegetais, principalmente em áreas de inundação permanente ou periódica, em agrupamentos mais ou menos homogêneos, sobre solos hidromórficos, formando populaçōes quase mono-específicas, às quais se dá o nome de miritizais ou buritizais (Storti, 1993; De Paula Fernandes, 2001).

As folhas de $M$. flexuosa são utilizadas para cobertura de habitações e suas fibras na confecção de artesanatos bem diversificados. Caracteristicamente, são restritas a uma coroa terminal dispostas em leque, com três a cinco metros de comprimento e dois a três de largura, costapalmadas, com inserção espiral, lâmina reduplicada, segmentada até quase a porção basal. São persistentes, com algumas mortas pendurando do topo, possuindo aproximadamente 200 segmentos foliares tesos ou pendulosos (Kahn, 1990; Cavalcante, 1991; Henderson et al., 1995; De Paula Fernandes, 2001).

M. flexuosa é restrita à América do Sul e bem distribuída por toda a região Amazônica, sendo utilizada por comunidades indígenas e extrativistas representando grande potencial econômico. No entanto, esta espécie ainda continua pouco explorada com relação a estudos que viabilizem o manejo de suas populaçōes (Cavalcante, 1991; De Paula Fernandes, 2001).

O conhecimento das características morfológicas e anatômicas das folhas das palmeiras é importante para entendimento das suas estruturas, fornecendo informaçōes para avaliar interaçōes ou mudanças evolutivas, além de fornecer subsídio para classificação deste grupo de plantas, já que poucas são as informaçōes sobre a significância biológica da estrutura foliar das palmeiras e sua variação em relação a condiçôes ecológicas (Tomlinson, 1990).

\section{MATERIAL E MÉTODOS}

O estudo foi realizado com material coletado em um buritizal localizado na área verde do Campus da Universidade Federal do Amazonas - UFAM (03 04,34' S e 59 57,30’ W), dentro de uma das maiores áreas verdes urbanas tropicais do mundo e, considerada o segundo maior fragmento florestal urbano do Brasil, na cidade de Manaus, com uma área de aproximadamente 800 hectares, dos quais cerca de 600 pertencentes à UFAM. O material botânico coletado e identificado foi depositado no Herbário da Universidade Federal do Amazonas (HUAM), sob o número 7282.

Do buritizal escolhido foram definidos indivíduos em três fases de desenvolvimento: fase jovem (vegetativa), com altura entre três a quatro metros evidenciando-se apenas as folhas; fase intermediária (vegetativa), com cerca de nove a dez metros de altura, com o estipe envolto por bainhas; fase adulta (reprodutiva), apresentando estipe definido e altura entre 15 e $25 \mathrm{~m}$, caracterizando-se pela presença de inflorescências e/ou frutos. Dentro de cada categoria definida, foram escolhidos cinco indivíduos. Segmentos foliares, de indivíduos de cada categoria foram coletados e fixados em $\mathrm{FAA}_{50}$ (Formol - Ácido acético Álcool) segundo Johansen (1940) e posteriormente encaminhados ao Laboratório de Botânica Agroflorestal da Universidade Federal do Amazonas (LABAF/UFAM), onde foram submetidos às técnicas usuais em anatomia vegetal.

Para a dissociação epidérmica foram utilizadas solução de Jeffrey (Johansen, 1940) e as técnicas de Franklin (1946), coradas com astrablau e safranina e as lâminas montadas com bálsamo do Canadá (Kraus \& Arduim, 1997).

Os cortes dos segmentos foliares foram realizados nas regiōes da base, meio e ápice dos mesmos. As amostras foram desidratadas e incluídas em parafina (Kraus \& Arduim, 1997), sendo realizados cortes histológicos com $11 \mathrm{~mm}$ de espessura em sentido transversal e longitudinal utilizando-se para tal micrótomo rotativo. As lâminas foram desparafinizadas, coradas com safranina e astrablau, e montadas em bálsamo do Canadá (Johansen, 1940 modificado; Kraus \& Arduim, 1997).

A contagem dos estômatos foi efetuada em 30 campos por folha, tomados aleatoriamente, para as duas faces da epiderme (abaxial e adaxial), utilizando-se microscópio óptico Carl Zeiss (aumento de 400x). Para os testes microquímicos foram realizados cortes do material fresco e, em seguida, tratados com corantes e reagentes específicos, para identificar possíveis presenças de óleos, amidos, lignina, sílica e taninos (Patiño, 1986; Kraus \& Arduim, 1997).

Para observações dos caracteres superficiais feitas em Microscopia Eletrônica de Varredura (MEV), segmentos foliares foram desidratados em série etílica, secos em ponto crítico de dióxido de carbono (equipamento EMITECH modelo K850) e metalizados em ouro (Bozzola \& Russel, 1991).

As imagens foram obtidas em fotomicroscópio Carl Zeiss Modelo Axioskop com câmera MC-80 e as eletrofotomicrografias obtidas de Microscópio Eletrônico de Varredura (MEV) JMS5400 LV, JEOL.1.

\section{RESULTADOS E DISCUSSÃO}

Nas regióes intercostais da epiderme adaxial dos segmentos foliares das três fases, encontram-se células predominantemente retangulares de paredes sinuosas, medindo entre 10,41 a 21,0 $\mu \mathrm{m}$ de comprimento, justapostas e orientadas no sentido longitudinal ao eixo do segmento foliar, quando em vista frontal (Fig. 1A, 1B), semelhantes às descritas por Pinheiro (1986) para Orbignya phalerata Mart.. 


\section{ACTA}

A sinuosidade das paredes das células epidérmicas é fortemente marcada na fase jovem, diminuindo gradativamente em relação às fases intermediária e adulta. Quanto à espessura, as paredes das células epidérmicas são mais espessas nos segmentos foliares dos indivíduos da fase adulta (Fig. 1A).

Araújo \& Mendonça (1998) nos resultados do seu trabalho com Aldina heterophylla Spruce ex Benth., relatam que a sinuosidade da parede das células epidérmicas está diretamente ligada à exposição das plantas ao sol ou a sombra e que o espessamento das paredes dessas células pode estar relacionado com a alta intensidade luminosa. Para Alquini et al. (2003), a sinuosidade da parede anticlinal está especialmente relacionada com o ambiente em que a folha se desenvolve. De acordo com Santiago et al. (2001), as paredes das células epidérmicas apresentam-se mais espessas; retas nas folhas a pleno sol e sinuosas nas folhas de sub-bosque, mostrando que as condições de ambiente como radiação solar influenciam o crescimento e o desenvolvimento dos tecidos vegetais.

Os indivíduos estudados de M. flexuosa se encontram em floresta umbrófila onde as folhas dos indivíduos jovens ficam em ambiente sombrio e as folhas dos indivíduos adultos ficam mais expostas ao sol. A menor sinuosidade e maior espessamento das paredes das células epidérmicas dos segmentos foliares na fase adulta podem estar relacionados com o estrato em que a planta se encontra na floresta, já que nesta fase as folhas estão mais expostas ao sol, em relação às outras duas fases estudadas.

$\mathrm{Na}$ região costal, as células epidérmicas da face adaxial de todas as fases de desenvolvimento apresentam-se com paredes retas, espessas e orientadas no sentido longitudinal do segmento foliar, variando na forma e apresentando estômatos dispersos.

A epiderme da face abaxial, na região intercostal de todas as fases, se apresenta com células justapostas, retangulares, com parede fortemente sinuosa e levemente espessa, em relação às células epidérmicas das faces adaxiais, orientadas no sentido longitudinal ao eixo do segmento foliar, onde se observa maior quantidade de estômatos dispostos em organizadas fileiras longitudinais ao eixo do segmento foliar (Fig. 1C).

$\mathrm{Na}$ região costal, as células epidérmicas da face abaxial também variam quanto à forma com paredes retas e espessas (Fig. 1D).

Em secção transversal as células epidérmicas dos segmentos foliares de ambas as faces e em todas as fases de desenvolvimento, apresentam-se uniestratificadas, de formato predominantemente quadrangular, de parede espessada, protegida por cutícula lisa e levemente espessa em toda a extensão do limbo, inclusive nas margens, sem projeções cuticulares ou depressōes significantes (Fig. 2A). A cutícula dá um aspecto brilhante à folha de $M$. flexuosa, sendo evidenciada a presença de lipídios por toda a extensão do limbo.

De acordo com Leite \& Scatena (2001), a epiderme com cutícula espessa em espécies do gênero Syagrus, está relacionada com a defesa destas plantas contra a dessecação, devido ao fato destas espécies crescerem em ambiente sujeito a estresse hídrico. Segundo Esau (1976), a espessura da cutícula é variável e influenciada pelas condições ambientais. De acordo com Menezes et al. (2003), as folhas das angiospermas apresentam grande variação de estruturas, devido à necessidade e disponibilidade ou não de água. A cutícula lisa, levemente espessa e sem projeções de $M$. flexuosa, pode estar relacionada com o bom suprimento hídrico do ambiente no qual é predominantemente encontrada.

Foram observados tricomas nos segmentos foliares de $M$. Flexuosa nas três fases de desenvolvimento estudadas, principalmente nas zonas costais da epiderme da face adaxial, apresentando-se simples, longos com a base mais espessa, afinando nas extremidades. Também foram visualizadas em vista frontal, bases de tricomas, formadas por aproximadamente cinco células cutinizadas em forma de roseta circundando uma célula central que se projeta externamente, formando um tricoma unicelular (Fig. 2B), semelhante ao encontrado por Mendonça et al. (1997) na epiderme foliar de Elaeis oleifera (Kunth) Cortês.

Kuniyoshi (1993) cita que pouco se conhece sobre o papel dos tricomas nas plantas, sendo estes características importantes para taxonomia, seja por sua ausência ou presença. De acordo com Tomlinson (1990), no gênero Cocos os tricomas são bastante
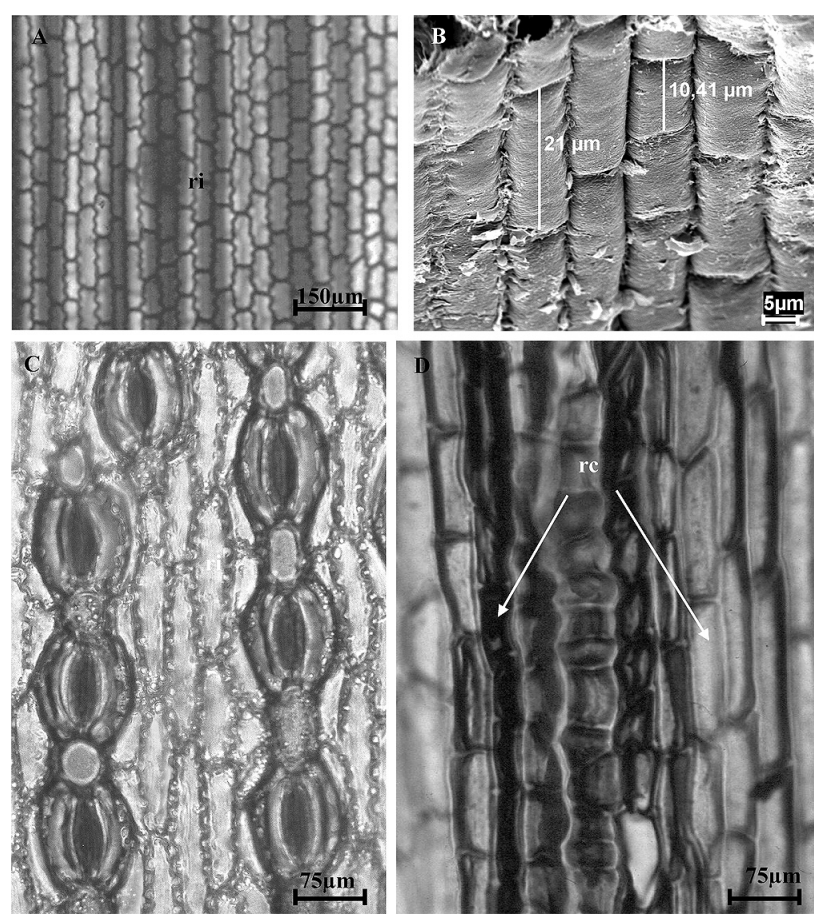

Figura 1 - Epiderme do segmento foliar de M. flexuosa na fase adulta. A) Epiderme adaxial na região intercostal com células retangulares, parede levemente sinuosa e espessa. B) Epiderme adaxial em MEV. C) Epiderme abaxial na região intercostal. D) Região costal mostrando células epidérmicas que variam em tamanho e forma (ri - região intercostal, rc - região costal). 
representativos, embora somente a base seja persistente nas folhas velhas, sendo característica importante nas palmeiras da tribo Caryoteae.

Para $M$. flexuosa a água não é um fator limitante já que as plantas se encontram em ambiente hidromórfico. Assim, a sua presença pode estar relacionada à defesa da planta contra herbivoria.

Em todas as fases estudadas foram observados corpos de sílica esférico-espinulosos, dispostos em fileiras longitudinais, em ambas as faces epidérmicas dos segmentos foliares por todas as extensões das lâminas foliares (Fig. 2C, 2D) e também acompanhando a distribuição das fibras, tal qual observado por Leite \& Scatena (2001), em espécies do gênero Syagrus.

Segundo Uhl \& Dransfield (1987), a dureza dos caules e das folhas das palmeiras resulta da presença de corpos de sílica em células especiais chamadas "stegmata" que estão associadas com fibras vasculares ou não vasculares e, também da forma desses corpos silicosos sendo este caráter, útil para diagnóstico. Leite \& Scatena (2001), destacam que a disposição enfileirada dos corpos silicosos pode ser um caráter taxonômico importante

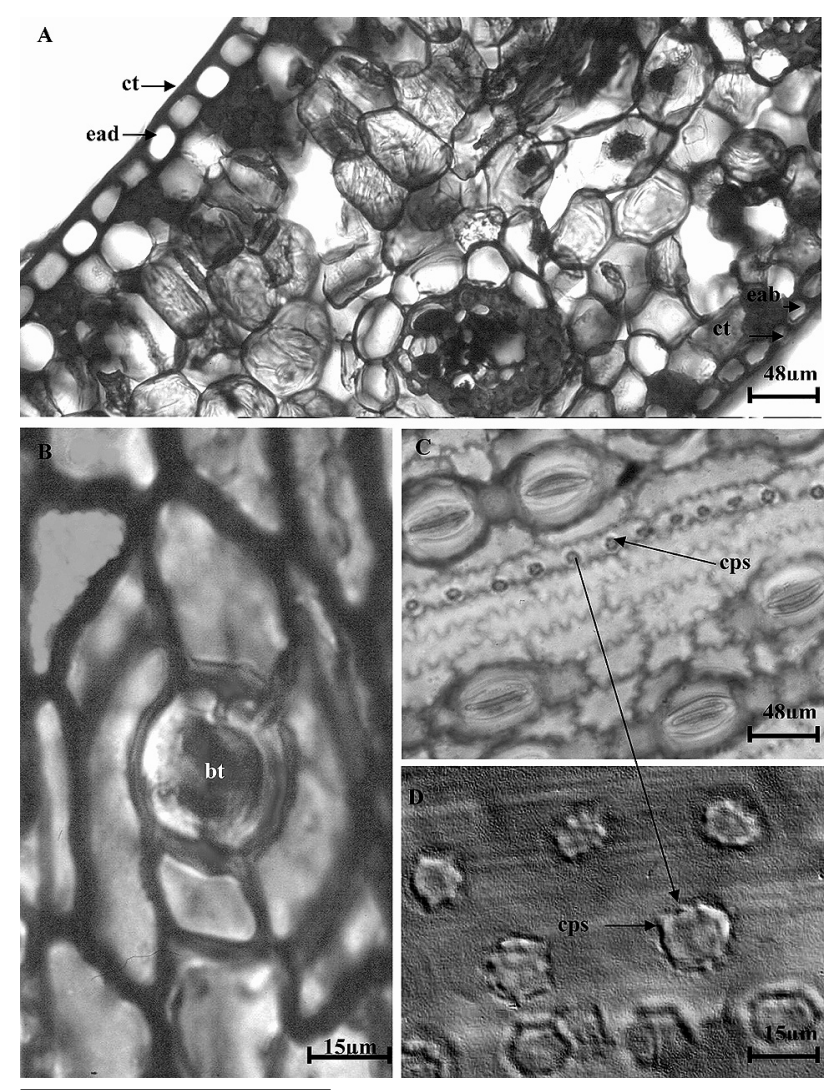

Figura 2 - Epiderme do segmento foliar de M. flexuosa. A) Corte transversal da epiderme. B) Base de tricoma na epiderme adaxial. C) Disposição dos corpos de sílica na epiderme. D) Detalhe dos corpos de sílica (ct - cutícula, ead - epiderme adaxial, eab - epiderme abaxial, bt - base de tricoma, cps corpo de sílica). para palmeiras do gênero Syagrus além de estar relacionada com a defesa destas plantas contra a dessecação e a herbivoria, pois, a presença de corpos de sílica nos tecidos superficiais previne o colapso dos tecidos adjacentes em condiçōes de seca, servindo também como uma proteção mecânica contra o ataque de insetos (Metcalfe, 1985).

Em M. flexuosa a forma dos corpos silicosos, esférico espinulosos, pode ter caráter taxonômico importante para a espécie e provavelmente a presença destas estruturas está relacionada com a defesa da planta contra herbivoria. A ocorrência de sílica em células epidérmicas, também é observada em outras espécies de palmeiras, o que parece ser comum a este grupo de plantas.

De um modo geral, a ocorrência de sílica em plantas tem sido relacionada como importante ao nível do metabolismo, porém muito longe de ser compreendida, pois há evidências de que a taxa de transpiração decresce pela deficiência em sílica (Kuniyoshi, 1993). De acordo com Mady (2003) o aparecimento de corpos de sílica pode indicar incapacidade para excluir o silício dissolvido na água absorvida pela planta.

Em vista frontal, a epiderme abaxial apresenta estômatos dispostos em longas e organizadas fileiras longitudinais ao eixo do segmento foliar (Fig. 3A), o que também foi observado em Elaeis oleifera por Mendonça et al. (1997). Na epiderme da face adaxial os estômatos são raros e orientados de forma mais dispersa, restringindo-se principalmente às regiôes costais.

O complexo estomático é formado por um par de células guardas, um par de células subsidiárias paralelas, e nas extremidades, duas outras células subsidiárias polares menores, de formato arredondado, constituindo estômatos do tipo tetracítico (Fig. 3B), de acordo com a revisão de Baranova (1987). Uma camada delgada de cera epicuticular proteje o estômato, cujo tipo tetracítico parece ser comum à maioria das palmeiras. (Fig. 3D).

Em secção transversal as células estomáticas estão situadas no mesmo nível das demais células epidérmicas, por toda a extensão da lâmina foliar, inclusive nas margens. Verifica-se também a presença de câmara subestomática ampla (Fig. 3C), o que pode estar relacionado não só com a troca gasosa, mas possivelmente também auxiliando na aeração, já que a planta está sujeita a inundação.

Utilizando a classificação de Metcalf \& Chalk (1972), considerou-se o segmento foliar de $M$. flexuosa como anfiestomático, mesmo com os estômatos praticamente concentrados na face abaxial nos segmentos foliares das três fases estudadas, pois estes também são visualizados esporadicamente nas zonas costais das faces adaxiais. Segundo Alquini et al. (2003), as folhas anfiestomáticas, com maior número de estômatos na face abaxial, podem ainda ser classificadas como anfihipoestomáticas. 

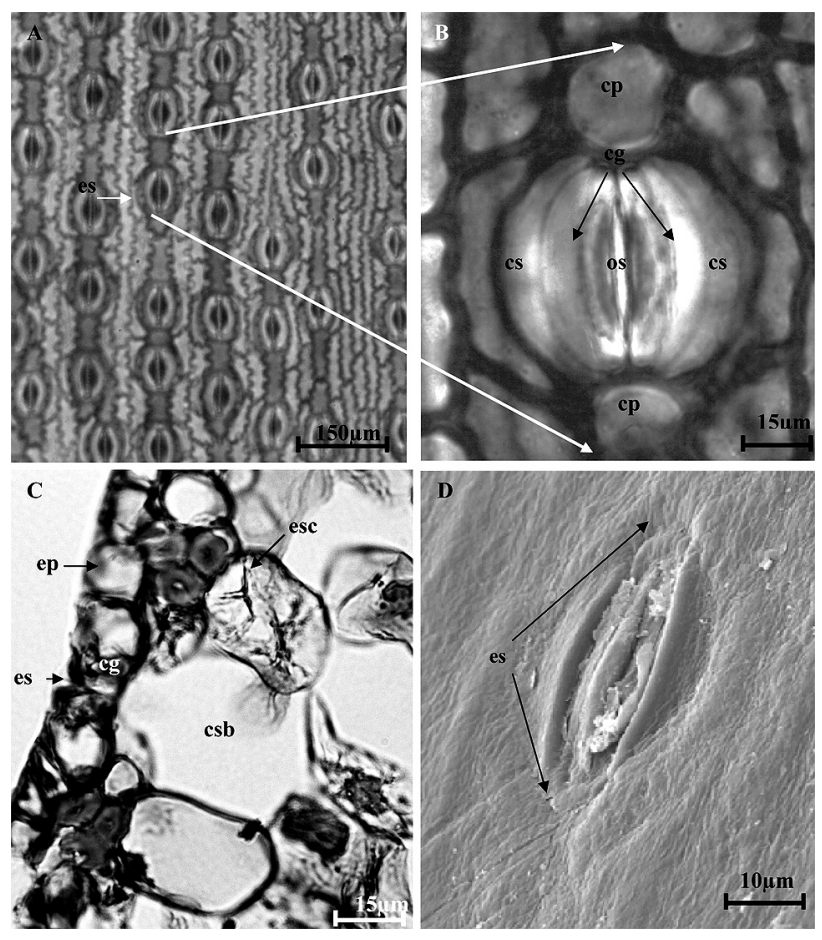

Figura 3 - Estômato em M. flexuosa. A) Disposição enfileirada dos estômatos na epiderme abaxial. B) Complexo estomático, estômato tetracítico. C) Estômato em corte transversal com câmara subestomática e esclerócito. D) Estômato em MEV, protegido por cera epicuticular (es - estômato, ep epiderme, $\mathbf{c g}$ - célula guarda, cs - célula subisidiária, cp - célula polar, os ostíolo, csb - câmara subestomática, esc - esclerócito).

Nas três fases estudadas, a fase intermediária é a que apresenta a maior quantidade de estômatos com média de 10,8 est. $\mathrm{mm}^{-2}$ na face adaxial e 581 est. $\mathrm{mm}^{-2}$ na face abaxial, seguida da fase adulta com 3,3 est. $\mathrm{mm}^{-}{ }^{2}$ na face adaxial e 535 est. $/ \mathrm{mm}^{2}$ na face abaxial e jovem com 2,6 est.mm- ${ }^{2}$ na face adaxial e 405 est.mm${ }^{2}$ na face abaxial, não ocorrendo diferença expressiva entre as fases.

A diferença encontrada entre as faces abaxiais e adaxiais da epiderme dos indivíduos, com relação ao número de estômatos, pode estar relacionada com fatores ambientais tal como intensidade de luz e umidade relativa do ar, pois segundo Kuniyoshi (1993), o número de estômatos pode ser influenciado por condiçôes ambientais, variando nas diferentes partes da folha, em diferentes folhas de um mesmo indivíduo ou da mesma espécie de diferentes idades. Bonates et al. (2000), destacam a importância da umidade relativa em ambientes tropicais onde os microclimas mais xéricos favorecem o aumento do número de estômatos, desde que a umidade relativa seja suficientemente alta para evitar a desidratação excessiva.

\section{BIBLIOGRAFIA CITADA}

Alquini, Y.; Bona, C.; Boeger, M.R.T.; Costa, C. G.; Barros, C. F. 2003. Epiderme. In: Glória, B.A.; Guerreiro, S.M.C. (Eds.). Anatomia Vegetal. UFV, Viçosa. p. 87-107.
Araújo, M.G.P.; Mendonça, M.S. 1998. Escleromorfismo foliar de Aldina heterophylla Spruce ex Benth. (Leguminosae: Papilionoideae) em três campinas da Amazônia Central. Acta Amazonica, 28(4): 353-371.

Baranova, M.A.; 1987. Historical development of the present classification of morfological types of stomates. The Botanical Review, 53: 53-79.

Bonates, L.C.M.; Barbosa, E.M.; Miranda, I.P.; Rabelo, A. 2000. Anatomia foliar de mumbaca (Astrocaryum gynacanthum Mart.). Resumos do LI Congresso Nacional de Botânica, Brasília. p.108.

Bozzola, J.J.; Russel, L.D. 1991. Electron microscopy. Jones and Bartlett Publishers. Boston. 542p.

Cavalcante, P.B. 1991. Frutas comestiveis da Amazônia. 5.ed. Edições CEJUP. CNPq: Museu Paraense Emílio Goeldi, Belém. 279p.

De Paula Fernandes, N.M. 2001. Estratégias de produção de sementes e stabelecimento de plântulas de Mauritia flexuosa L.f. (Arecaceae) no Vale do Acre, Brasil. Tese de Doutorado, Instituto Nacional de Pesquisas da Amazônia/ Universidade Federal do Amazonas, Manaus, 203p.

Esau, K.; 1976. Anatomia de plantas com sementes. Editora Edgard Blücher, São Paulo. 393p.

Franklin, G.L. 1946. A rapid method of softening wood for microtome sectioning. Australian Journal of Botany, 33: 393408.

Henderson, A.; Galeano, G.; Bernal, R. 1995. A field guide to the palms of the Americas. Princeton University Press, New Jersey. $351 \mathrm{p}$.

Johansen, D.A. 1940. Plant microtechnique. Mc Graw-Hill Book, New York. 523p.

Kahn, F. 1990. Clave para diferenciar los géneros de palmae em la Amazonia a partir del aparato vegetativo. Bull. Inst. Fr. Etudes Andines, 19(2): 351-378.

Kraus, J.E.; Arduim, M.; 1997. Manual básico de métodos em morfologia vegetal. EDUR, Rio de Janeiro. 189p.

Kuniyoshi, Y.S. 1993. Aspectos morfo-anatômicos do caule, raiz e folha de Tabebuia cassinoides (Lam.) DC. (Bignoniaceae) em diferentes fases sucessionais no litoral do Paraná. Tese de doutorado, Universidade Federal do Paraná,Curitiba. 130p.

Leite, K.R.; Scatena, V.L.; 2001. Anatomia do segmento foliar de espécies de Syagrus Mart. (Arecaceae) da Chapada Diamantina, Bahia, Brasil. Sitientibus. Série Ciências Biológicas, 1(1): 3-14.

Mady, F.T.M. 2003. Aspectos da Anatomia do estipe de Euterpe oleracea Mart.. (Arecaceae): Palmeira utilizada em sistemas agroflorestais. Dissertação de Mestrado, Universidade Federal do Amazonas, Manaus. 30p.

Mendonça, M.S.; Brock, E.; Aguiar, M.O. 1997. A epiderme foliar do Caiauê (Elaeis oleifera (Kunth) Cortés). Rev. UA. Série Ciências Agrárias, 6(1/2): 37-44.

Menezes, N.L.; Silva, D.C.; Pinna, G.F.A.M. 2003. Folha. In: Glória, B. A.; Guerreiro, S. M. C. (Eds.). Anatomia Vegetal. Editora UFV, Viçosa. p. 303-325.

Metcalf, C.R.; Chalk, L. 1972. Anatomy of the Dicotyledons. Vol. 2. Clarendon Press, Oxford. 1500p. 


\section{ACTA

Metcalf, C.R. 1985. Silica. In: Metcalfe, C.R.; Chalk L. (Eds.). Anatomy of Dicotyledons. Claredon Press, Oxford. 2: 91-94.

Patiño, J.C. 1986. Microtecnia Vegetal. Trillas, México.106p.

Pinheiro, C.U.B. 1986. Anatomia da folha de Orbignia phalerata Martius, O. eichleri Drude e O. teixeirana Bondar (Palmae). Empresa Brasileira de Pesquisas Agropecuárias - EMBRAPA. Boletim de pesquisa. 10: 7-31.

Santiago, E.J.A.; Pinto, J.E.B.P.; Castro, E.M.; Lameira, O.A.; Conceição, H.E.O. 2001. Aspectos da anatomia foliar da pimenta-longa (Piper hispidinervium C. DC.) sob diferentes condiçōes de luminosidade. Ciências agrotécnicas, 25(5): 10351042 .
Storti, E.F. 1993. Biologia floral de Mauritia flexuosa Lin. fil., na região de Manaus, Amazonas, Brasil. Acta amazonica, 23(4): 381.

Tomlinson, P.B. 1990. The strutuctural biology of palms. Clarendon Press, Oxford. 465p.

Uhl, N.W.; Dransfield, J. 1987. Genera palmarum: a classification of palms based on the work Harold E. Moore, Jr. Allen Press, Lawrence, Kansas. 610p.

Recebido em 27/07/2005

Aceito em 23/11/2006 